\title{
CONTRIBUTIONS OF LOGISTICS CLUSTERS TO CITY ECONOMY AND LOCAL PEOPLE: TURKOGLU LOGISTICS VILLAGE EXAMPLE
}

DOI: 10.17261/Pressacademia.2020.1239

PAP- V.11-2020(11)-p.52-56

Zumrut Hatice Sekkeli ${ }^{1}$, Ismail Bakan ${ }^{2}$, Halil Ibrahim Olucak ${ }^{3}$

${ }^{1}$ Kahramanmaras Sutcu Imam University, Turkoglulu Vocational School, Management and Organisation Dept., Kahramanmaras, Turkey. zhkiper@yahoo.com, ORCID: 0000-0001-5090-4372

${ }^{2}$ Kahramanmaras Sutcu Imam University, Bussiness Department, Kahramanmaras, Turkey. ibakan63@hotmail.com, ORCID: 0000-0001-8644-8778

${ }^{3}$ Kahramanmaras Sutcu Imam University, Bussines Management, Kahramanmaras, Turkey. halilolucak@gmail.com, ORCID: 0000-0000-0000-0000

To cite this document

Sekkeli Z., H., Bakan I., Olucak H., I., (2020). Contributions of logistics clusters to city economy and local people: Turkoglu logistics village example. PressAcademia Procedia (PAP), V.11, p. 52-56

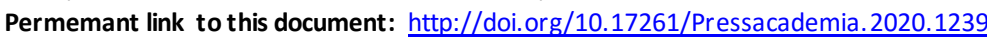

Copyright: Published by PressAcademia and limited licensed re-use rights only.

\section{ABSTRACT}

Purpose - The aim of the study is to measure the perspectives of the participants that live in Kahramanmaras province, to determine the ir attitudes about the Logistics Village (LV) that established in this province and to raise awareness by this way

Methodology - For this purpose, the 5-point Likert scale survey was conducted by the participants living and working in the province of Kahramanmaras in June 2019 with simple random sampling method. The data is analysed by frequency, mean, standard deviation va lues, $t$ test and Anova.

Findings- The average values of all propositions are 3.68; $18 \%$ have well enough knowledge about LV; there was a significant difference between "working times" and "levels of knowledge about LV ", but there was not significant difference in gender, age and educational status. Conclusion- Although the local people are not well-informed enough about the LV concept, the participants had a positive attitude to the LV will contribute to the city economy.

Keywords: Logistics center, freight villages, clustering, Türkoğlu Logistics Village.

JEL Codes: L80, H10, L91

\section{LOJISTIK KÜMELENMELERININ ŞEHIR EKONOMISINE VE YÖRE HALKINA KATKILARI: TÜRKOĞLU LOJISTiK KÖYÖRNEĞi}

\section{ÖZET}

Amaç- Çalışmanın amacı Kahramanmaraş ilinde yaşayan katılımcıların bakış açılarını ölçmek, bu ilde kurulan Lojistik Köyü (LK) ile ilgili tutumlarını belirlemek ve bu yolla farkındalıklarının artmasını sağlamaktır.

Yöntem- Bu amaçla Kahramanmaraş ilinde yaşayan ve çalışan katılımcılar tarafından Haziran 2019 'da basit rastgele örnekleme yöntemi ile $5^{\prime}$ li Likert ölçekli bir anketi uygulanmıştır. Elde edilen verilere ilk olarak frekans, ortalama, standart sapma değerleri, sonra da t testi ve Anova analizleri uygulanmıştır.

Bulgular- Tüm önermelerin ortalama değerleri 3.68'dir; sadece \%18'i LK hakkında yeterince bilgiye sahip olduğunu belirtmiştir; "Çalışma süreleri" ile "LK hakkında bilgi düzeyleri" arasında anlamlı bir fark bulunmakta, ancak cinsiyet, yaş ve eğitim durumu arasın da anlamlı bir fark bulunmamaktadır.

Sonuç- Yerel halk LK kavramı hakkında yeterince bilgili olmasa da LK'nin şehir ekonomisine katkı sağlayacağına dair olumlu bir tutum sergilemişlerdir.

Anahtar Kelimeler: Lojistik merkezi, yük köyleri, kümeleme, Türkoğlu Lojistik Köyü, JEL Kodları: L80, H10, L91.

\section{GiRiş}

İşletmeler küreselleşme, teknolojik gelişmeler, yeni ekonomi anlayışı ve rekabetin farklılaşması sonucunda rekabet etmekte zorlanmaya başlamışlardır. Bu nedenle kendilerine ulusal ve/veya uluslararası pazarlarda rekabet avantajı sağlamak için mevcut süreçlerin 
iyileştirilmesine yönelik çeşitli arayışlara girmişlerdir (Bakan ve Şekkeli, 2017: 15). Tüm bu arayışlar sonucunda Kümelenme Yapılanması (cluster formation) yaklaşımı ön plana çıkmıştır. Devletler kendi ülkelerinin, bölgelerinin ve ülke sınırları içinde faaliyette bulunan işletmelerin rekabet etme gücünü artırmak ve ulusal refahı geliştirmek amacıyla dünyanın dört bir yanında sektörel kümelenmeye yönelik politikalar başlatmışlar, hatta bazıları, kalkınmaya yönelik vizyon ve planlarını direkt kümelenme yaklaşımı üzerinden yapmaya başlamışladırlar (Eraslan ve Dönmez, 2017: 720).

Dünya genelinde yalnızca endüstriyel nedenlerle değil; hizmet sektörü için de kümelenmeler oluşturulmaktadır. Lojistik kümele nmeler de bu kümelenmelerden biri olarak karşımıza çıkmaktadır (Yıldırım ve Demet, 2016: 397). Çünkü lojistik süreçlerin rekabet edebilmek açısından kritik öneme sahip olması sebebiyle; bu faaliyetlerle alakalı tüm proseslerin en etkin bir şekilde yönetilebilmesi için bütün taşıma modalarıyla direkt ya da dolaylı bir bağlantısı olan; içinde taşıma, depolama, elleçleme, tartma, bölme veya birleştirme, ambalajlama vs. faaliyetlerin yapıldığı; müşterilerine maliyet ve hız avantajı sağlayan; gereken tüm altyapı ve donanımlarına sahip olan; adına da "lojistik köy" adı verilen stratejik kümelenmeler oluşturulmaya başlanmıştır (Dursun ve Gürsev, 2016: 556).

Bu kümelenme ülkemizde Ulaştırma, Denizcilik ve Haberleşme Bakanlığı tarafından ilk olarak “lojistik köy" olarak adlandırılmışsa da sonralar "lojistik merkez" ismini kullanmayı tercih etmişlerdir. Bunun dışında yük köyü, lojistik alan, lojistik merkez, lojistik odak, lojistik park, lojistik üs, dağıtım parkı gibi farklı adlandırmalar da yapılmaktadır (Terzi ve Bölükbaş, 2016: 213)

Lojistik köylerinin işletmelere maliyet avantajı, rekabet gücü, işlevsel kolaylıklar vs. sağlamaları yanında toplumsal ve ekonomik açıdan bölgenin kalkınmasına da büyük katkıları bulunmaktadır. Bu çalışmada Türkoğlu lojistik köyünün, bu bölgeye sağlayacağı toplum sal ve ekonomik katkılara yönelik katılımcıların bakış açılarının ölçülmesinin ve bu konuda bir farkındalık yaratılması amaçlanmaktadır. Bu ama çla çalışmanın 2. bölümünde lojistik köy kavramının ne olduğu açıklanmaya çalışımış, 3. bölümünde ise araştırmanın metodolojisi ve bulgularına yer verilmiştir.

\section{LITERATÜR INNCELEMESI}

Lojistik kümelenmeler 1980' den sonra Avrupa Ülkeleri'nde ticaret hacminin ve ulaşımın artmasıyla oluşan çevre kirliliği ve şe hirlerde yaşanan başka sorunlar nedeniyle oluşturulmaya başlanmıştır (Yıldırım ve Demet, 2016: 397). Lojistik köy kavramı, ilk olarak Massachusetts Teknoloji Enstitüsünde görev yapan Prof. Y. Sheffi tarafından 2010 yılında lojistik yoğun kümelenmeler olarak, 2012 yılında ise lojistik kümelenmeler olarak tanımlanmıştır.

Lojistik köy, ürünlerin hem ulusal hem de uluslararası geçişlerde çeşitli ticari firmaların gerçekleştirdiği taşıma, lojistik ve dağıtım ile ilgili tüm faaliyetlerin yapıldığı, mastır planlara uygun, bir merkezden yönetilen, son teknoloji olanaklarına sahip, yüksek güvenlikli bir alan olarak tanımlanmaktadır. Bu firmalar o alana inşa edilmiş olan depo, dağıtım merkezleri, ofisler gibi tesislerin sahibi olabildikleri gibi kiracı firmalar da olabilmektedirler (http://www.europlatforms.eu/, Erişim tarihi: 05/01/2019; Gedik, 2017:131). Bir diğer tanıma göre ise, lojistik kümelenme; katma değerli hizmet sunmak için deniz, hava, demir yolu gibi çeşitli ulaştırma modlarının ortaklaşa faaliyette bulunduğu y eri ifade etmektedir (Terzi ve Bölükbaş, 2016: 212)

Lojistik köy, sanayi bölgeleri, iş merkezleri gibi büyük ve önemli üretim merkezlerinin civarına; demiryolu ve karayolu hatları ile (mümkünse) limanlarla bağlantılı yerlere ve şehirlerin yakınlarına konumlandırılmaktadırlar (TCDD, 2017). Ekonomik büyümenin ve verimliliğin arttırılmasında, sadece işletmelere değil aynı zamanda bulunduğu bölgenin kalkınmasında da etkili olan lojistik kümelenmeler (Zaralı, Yazgan ve Delice, 2019: 2), yerel topluluklar tarafından kendi refahlarını güçlendirmek yani ekonomik ve sosyal faydalar elde etmek için önemli firsatlar sunmaktadır (Michael, 2003).

Bir ulaşım terminali çevresinde bulunan aynı tesislerin, donanımların ve alt yapıların kullanıldığı bir kümelenme türü olan lojistik köylerin, lojistik faaliyetler gerçekleştirilirken birbiri ile bağlantısı bulunan ya da direkt bağlantısı bulunmayan çok çeşitli sektörlerden kurumlara büyük pozitif etkileri olmaktadır. Bu etkiler: ekonomik, çevresel, sektörel ve sosyal olmak üzere dört çeşittir (EUROPLATFORMS, 2015);

Sosyal Faydalar, mallarını satma ve kiralama fırsatları, kültürel çeşitlilik, restoran, otel vs. gibi sosyal alanlarda ve laboratuvarlar, te knik ve finansman danışma kurumları gibi destek birimlerinde artış gibi yöre halkında olacak pozitif değişiklikler olarak adlandırı Imaktadır.

Ekonomik Faydalar; Bölgesel açıdan ekonomik büyümenin ve yatırımın teşvik edilmesi, gelirlerin artması, yeni iş alanlarını oluşturması nedeniyle istihdamda artış yaratması, yerel mutfaklar, yöresel gelenekler, kıyafetler vb. öğelerle kültür tur izmine zemin hazırlaması gibi bölgenin ekonomik gelişimine sağladığı katkılar olarak tanımlanabilmektedir.

Sektörel Faydalar; İşletmelerin üretkenliğini ve verimliliğini artırmak, yenilikçiliği teşvik etmek, hammaddeye, hizmetlere veya kalifiye işgücüne kolayca ve hızlıca ulaşabilme imkânı sunmak, maliyeti düşürmek, markalaşmaya teşvik etmek; sanayi, üniversite, devlet ve sivil toplum kuruluşlarının işbirliği kurmasını sağlamak gibi faydalardır.

ÇevreselFaydalar, çevre bilincinin gelişmesine ve çevrenin korunmasına yönelik sunduğu faydalardır (Aydemir ve Soydaş, 2014: 15; Gökdeniz, 2015: 41; Günaydın, 2017: 19)

Illk olarak ABD' de ortaya çıkan Lojistik köy kavramı, 1967 yılında Avrupa'da Fransa' da da görülmeye başlanmıştır (http://www.s ogaris.fr Erişim tarihi 10.05.2019). 60'ların sonu ve 70'lerin başında İtalya ve Almanya' da da yer almaya başlamış; 90'lı yıllarda da Fransa, Alma nya, İtalya, Hollanda, Belçika, İngiltere gibi birçok Avrupa ülkesinde yaygınlaşmıştır (Akandere, 2013: 48). Günümüzde dünya genelinde Hong Kong, Antwerp, Şangay, Rotterdam, Hamburg, Singapur, Dubai, Tokyo, Los Angeles, New York, Paris gibi birçok şehirde birçok ön emli lojistik merkezler bulunmaktadır (Akçetin, 2010: 3).

Türkiye ise ilk olarak Lojistik köy kavramı ile 2006 yılda Ulaştırma Bakanlığı TCDD yatırım programında yer alması ile tanışmıştır. O günden bugüne, yapılması planlanan toplam 21 lojistik merkezinden; Mersin (Yenice) ve Konya (Kayacık) olmak üzere 2 tanesinin inşası tamamlanmış, 
İzmir (Kemalpaşa) ve Kars olmak üzere 2 tanesinin de inşası devam etmektedir. Lojistik köylerden 8 tanesi de (Bilecik (Bozüyük), İstanbul (Avrupa yakası), Karaman, Kayseri, Sivas, Bitlis (Tatvan), Habur ve Mardin) ihale sürecindedir. Samsun (Gelemen), İstanbul (Halkalı), Balıkesir (Gökköy), Denizli (Kaklık), Eskişehir (Hasan Bey), İzmit (Köseköy), Erzurum (Palandöken), Uşak ve Kahramanmaraş (Türkoğlu) olmak üzere 9 tanesi işletmeye açılmıştır (TCDD, http://www.tcdd.gov.tr/content/33: Erişim tarihi 10.05.2019).

\section{YÖNTEM}

Küreselleşme sadece ülkeleri etkilemekle kalmamış, şehirleri ve hatta ilçeleri bile rekabetçilik açısından derinden etkilemiş tir. Lojistik alt yapısı güçlü olan şehirler büyürken; lojistik alt yapısı ile ilgili sorunlar yaşayan şehirler onların gerisinde kalmışlardır. Bunlardan bir tanesi de Kahramanmaraş'tır. Bu çalışma ile Kahramanmaraş gibi yüksek potansiyele sahip bir şehrin, Türkoğlu ilçesinde kurulan ancak ta m olarak kullanıma açılmayan lojistik köy kümelenmesinin, şehir ekonomisine ve yöre halkına sağlayacağı katkılara dair algılarını ölçmek ve lojistik konusunda farkındalık yaratmak amaçlanmıştır.

Bu amaçla aşağıdaki hipotezler türetilmiştir:

H1: Katılımcıların cinsiyeti ile lojistik kümelenmenin şehir ekonomisine ve yöre halkına sağlayacağı katkılara dair algısı arasında anlamlı bir farklılık vardır.

H2: Katılımcıların yaşı ile lojistik kümelenmenin şehir ekonomisine ve yöre halkına sağlayacağı katkılara dair algısı arasında anlamlı bir farklılk vardır.

H3: Katılımcıların eğitim durumu ile lojistik kümelenmenin şehir ekonomisine ve yöre halkına sağlayacağı katkılara dair algısı arasında anlamlı bir farklııı vardır.

H4: Katılımcıların çalıştıkları süreyle lojistik kümelenmenin şehir ekonomisine ve yöre halkına sağlayacağı katkılara dair algısı arasında anlamlı bir farklılık vardır.

H5: Katılımcıların bilgi düzeyi ile lojistik kümelenmenin şehir ekonomisine ve yöre halkına sağlayacağı katkılara dair algıSı arasında anlamlı bir farklılık vardır.

Kahramanmaraş'ta faaliyet gösteren işletmelerde çalışan yöre halkının lojistik kümelenmeyle ilgili algılarının araştırıldığı bu çalışmada, öncelikle ilgili konularda yayımlanmış kitap, dergi, makale, tez vs. taraması yapılmıştır. Daha sonra örneklem olarak seçile $n$ işletmelere araştırma konusu ile ilgili 22 önermenin yer aldığı ve iki bölümden oluşan bir anket uygulanmıştır. Birinci bölümde, katılımcılara ve işletmelere dair demografik bilgileri; ikinci bölümde ise katılımcıların lojistik kümelenmenin sunacağı katkılara dair algılarını ölçmeye yönelik önermeler yer almaktadır.

Anket ölçeği oluşturulurken Gürbüz, Ayaz ve Kebeci'nin (https://www.resmigazete.gov.tr/eskiler/2016/08/20160823-3.htm) “Üretim işletmeleri Yöneticilerinin Lojistik Köy Algıları: Karabük ili Örneği" isimli çalışmasından; Bay ve Erol'un (https://www.resmigazete.gov.tr/eskiler/2016/08/20160823-3.htm) “Lojistik Köylerin Önemi ve Intermodal Taşımacıllk Faaliyetleriyle Desteklenmesi: Karaman Illinde Bir Uygulama" isimli çalışmasından ve Gedik veTurgut' un (2017 SHGM) “Uluslararası Ticarette Lojistik Köylerin ihracat Sürecine Etkileri: Konya ili Örneği” isimli çalışmasından yararlanılmıştır. Ölçek sorularında 5’li Likert (Hiç Katılmıyorum, Az Katılıyorum, Orta Düzeyde Katılıyorum, Çok Katılıyorum, Tamamen Katılıyorum) kullanılmış ve veriler yüz yüze anket yöntemi ile toplanmıştır.

Araştırma evreni, zümrelere göre tabakalı ve basit tesadüfî örnekleme yöntemiyle belirlenmiştir. Bu amaçla Kahramanmar aş il merkezinde faaliyet gösteren Kahramanmaraş Ticaret Odasına kayıtlı, dış ticaret yapan ve gıda, kâğıt, çelik mutfak eşyası, tekstil, giyim vs. sektörlerde faaliyet gösteren 259 işletme tespit edilmiştir. Örneklem büyüklüğü, 0.05 örneklem hatası p=0,5 ve q=0,5 güven aralığında 155 olarak hesaplanmıştır. Bu amaçla örneklem sayısından fazla (200 adet) anket dağıtılmıs 156 anket toplanmıştır.

Araştırma verilerinin analizi kapsamında ilk olarak ankette yer alan önermelerin güvenilirliği test edilmiş, ikinci adımda örnekleminin frekans ve yüzde dağılımları analiz edilerek demografik özellikleri belirlenmiş; üçüncü adımda katılımcıların lojistik kümelenmenin şehir ekonomisine ve yöre halkına sağlayacağı katkılara dair algılarına ilişkin önermelerin, frekans analizi, aritmetik ortalama ve standart sapma değerleri analiz edilmiştir. Son bölümde ise gruplar arasında ortalamalar açısından fark olup olmadığını belirlemek amacıyla $t$ testi ve Varyans Analizi uygulanmıştır.

Sosyal bilimler alanında yapılan çalışmaların genel sınırlııkları bu araştırma için de geçerlidir. Ayrıca çalışma Kahramanmaraşilinde faaliyet gösteren ve Ticaret odasına kayıtlı dış ticaret yapan firmalarla sınırlıdır. Araştırma kapsamındaki ilgili kişiler yörede hem yaşayan hem de çalışan ve lojistik köy hakkında bilgi sahibi olan kişilerdir. Bu nedenle araştırılan konuya dair bakış açılarını ve farkındalıklarını yansıtabilecek durumdadırlar. Çalışmada kullanılan anket yönteminin bünyesinde var olabilecek bazı eksikliklerin sonuç üzerinde etkili olabileceği intimali göz ardı edilmemelidir

\section{BULGULAR}

Öncelikle değişkenlerin ölçeklerinin güvenilirliklerini ölçmek için güvenilirlik analizleri yapılmış; Cronbach's $\alpha$ değeri 0,905 olarak hesaplanmıştır. Daha sonra ise ankete katılanların demografik özelliklerine ilişkin veriler analiz edilmiş ve \%71,0'nın erkek, \%41,7'sinin bekâr, $\% 85,9$ ' unun 40 yaşının altında; \%57,1'inin lisans mezunu ve \%55,8' inin ise farklı kademelerde görev yapan yöneticiler olduğu bulgularına ualışmıştır.

Katılımcıların lojistik köy kavramı hakkında bilgi sahibi olma düzeyleri incelendiğinde ise \%25'lik bir kısım bu konuda çok az bilgilerinin olduğunu belirtirken \%33'ü de az bildiklerini, \%37'si orta düzeyde, \%9'u iyi düzeyde bildiklerini ifade etmişlerdir. Bu konuya hâkim olduğunu belirten katılımcı yüzdesi ise \%9 gibi oldukça düşük düzeydedir. Bilgisi olmadığını ifade edenlere ise anket uygulanmamıştır. 
Ankete katılanlara, lojistik kümelenmenin sağlayacağı katkıları ölçen 22 önerme sunulmuştur. Bu önermelere bakıldığında hepsinin 3 'den büyük 4'e yakın değerlerde olduğu görülmektedir. Anket sonuçlarına göre "Kahramanmaraş'ın Akdeniz bölgesi ve Güney Doğu Anadolu bölgesi arasında stratejik konumu nedeniyle lojistik köyü şehre avantaj sağlayacaktır." önermesi 4,10 ile en yüksek değere sahiptir. İkinci yüksek önerme ise 3,95 ortalama ile "Kahramanmaraş'ın konumunun Ortadoğu ülkelerine yakın olması nedeniyle lojistik köyü şehre avantaj sağlayacaktır" önermesidir. Bu önermeyi 3,94 ortalama ile Lojistik köy sayesinde dış ticaret yapmak kolaylaşacaktır" önermesi takip etmektedir. Yine 3,94 ortalaması ile "Lojistik köyü, Kahramanmaraş ilinin dış çevreye doğru bir biçimde tanıtımını sağlayacaktır", 3,91 ile "Lojistik köyü ile Kahramanmaraş'ın sınır komşuları arasında etkileşim daha fazla artacaktır" ve 3,90 ile "Lojistik köyler, ilimizdeki sanayi dışındaki diğer sektörlerin de gelişimine sinerji oluşturacaktır" önermeleri de yüksek ortalamaya sahiptirler .

"Lojistik köy nedeni ile nüfus artacağından ilimizde suç oranları artacaktır" önermesi 3,02 ile en düşük değere sahiptir . Bu önermeyi 3,11 ile “Lojistik köyler KOBi niteliğindeki işletmelere dezavantaj oluşturacaktır." önermesine izlemektedir. "Lojistik köy nedeni ile nüfus artacağından ilimizde yol, su, elektrik gibi alt yapı hizmetlerinde ve sağlık, eğitim gibi alanlarda hizmetler yetersiz kalacaktı" önermesi 3,18 ortala ma ile üçüncü düşük önermedir. Bu üç önerme de kararsıza yakın ortalamalara sahiptir. Daha çok karar veremeyenlerin olduğu görülm ekle beraber konuya olumlu ya da olumsuz yaklaşanların da oranı birbirine oldukça yakındır. Aslında katılımcıların lojistik köyün avantaj sağlarken yanı sıra dezavantaj da yaratıp yaratmayacağına dair tereddütlerinin olması da şaşırtıcı değildir. Çünkü her yenilik ve değişim belirsizlik içermektedir.

Katılımcıların lojistik köy algılarını ortaya çıkarılmasına önermelerin genel aritmetik ortalaması ile katılımcıların demografik özelliklerine arasında \%5 güven aralığında ( $p<0,05$ anlamlıık düzeyinde) anlamlı bir farklılık bulunup bulunmadığını tespit etmek için Bağımsız Örneklem t-Testi ve Tek Yönlü Varyans Analizi (OneWay ANOVA) testleri yapılmıştır. Bu analizlere göre katılımcıların lojistik kümelenme algılarına ilişkin önermelere verdiği cevaplarda, cinsiyet, yaş, eğitim durumları açısından anlamlı bir farklılk olmadığı, ancak çalışma süreleri ve lojistik kümelenme kavramını bilme düzeyleri arasında $(p=0,000 ; p \leq 0,05)$ anlamlı bir farklılı olduğu görülmüştür.

\section{SONUÇ VEÖNERILER}

Lojistik yönetimi işletmeler açısından kritik öneme sahiptir. Ürünlerin tedarik zinciri boyunca çıkış noktasından nihai tüketiciye varana kadar ki tüm aşamalarında etkin bir lojistik yönetiminin yapılması sadece işletmelere değil, ülke ekonomisine de büyük avantaj sağlamaktadır. Bu nedenle ülkeler lojistik faaliyetlerin tek merkezde toplandığı, çeşitli taşıma imkânları sunan, lojistik maliyetlerini düşüren, kurulduğu şehirde ve bölgede istihdamı ve refahı artıran, çevreye duyarlı, sektör içi sinerji yaratan ve sektörler arası etkileşimi artıran adına lojistik kümelenme dedikleri yığınlar (cluster-kümeler) oluşturmaya başlamışlardır. Tüm dünya genelinde Almanya, İtalya ve İspanya olmak üzere birçok ülkede bulunan ve farklı isimlerle anılsa da aynı amaçla oluşturulan birçok lojistik kümelenme bulunmaktadır. Türkiye'de de son yıllarda özellikle de TCDD tarafından bu kümelenmelerin yapımına ve işletilmesine büyük önem verilmeye ve daha fazla sayıda inşa edilmesine başlanm ıştır.

Literatür incelendiğinde yapılan birçok çalışmada lojistik kümelenmelerinin sektörel faydalarından bahsedilmiş ama toplumsal boyut yeterince irdelenmemiştir. Bu nedenle bu çalışmada bu bölgede ikamet eden ve çalışan insanların lojistik köye bakış açılarının ve köyün bölgeye ve yöre halkına sunacağı katkıların farkındalık düzeylerinin tespit edilmesi amaçlanmaktadır. Bu amaçla ilk olarak SPSS programı ile demografik özellikler daha sonra da ankette yöneltilen ifadelere verilen yanıtların frekans, ortalama ve standart sapma değerleri analiz edilerek yorumlanmıştır. Son olarak da grupları arasında ortalamalar açısından fark olup olmadığını tespiti için $t$ testi ve $V$ aryans Analizi uygulanmıştır.

Lojistik kümelenmesinin, bu bölgeye sağlayacağı ekonomik ve toplumsal katkılara dair farkındalık düzeyini anlamaya yönelik oluşturulan ölçekteki ifadelerin büyük çoğunluğunun ortalama değerinin 3'den (kararsız) fazla; 4'e (katılıyorum) yakın olduğu görülmüştür. Tüm önermelerin ortalama değerleri ise 3,68' dir. Anket sonuçlarına göre “Kahramanmaraş'ın Akdeniz bölgesi ve Güney Doğu Anadolu bölgesi arasında stratejik konumu nedeniyle lojistik köyü şehre avantaj sağlayacaktır." önermesi 4,10 ile en yüksek değere sahiptir. Bu önermeye sadece \%6,4'ü (9 kişi) olumsuz fikir beyan ederken \%79,1 gibi büyük bir oran (122 kişi) olumlu fikir beyan etmiştir. Kahramanmaraş Akdeniz Bölgesinin doğusunda bulunmakta ve hem kara hem de demir yolu ulaşımında güneyden ve Akdeniz'den gelen yolları doğuya ve kuze ye bağlayan önemli bir konumda yer almaktadır (https://www.e-sehir.com/; Erişim tarihi: 16.05.2019). Ayrıca iç Anadolu ve Doğu Anadolu da komşu olan şehir dört bölge arasında bir köprü görevi görmektedir. İkinci yüksek önerme ise 3,95 ortalama ile “Kahramanmaraş'ın konumunun Ortadoğu ülkelerine yakın olması nedeniyle lojistik köyü şehre avantaj sağlayacaktır” önermesi takip etmektedir. Bu önermeye sadece \%6,4'ü (9 kişi) olumsuz fikir beyan ederken \%78,2 gibi büyük bir oran (122 kişi) olumlu fikir beyan etmiştir. Bu değe rin çıkması beklentiye uygundur. Çünkü Türkiye'nin Ortadoğu ülkelerine ihracat oranı oldukça yüksektir ve genel olarak ithalata kıyasla daha fazla yapılmaktadır. 2017 verilerine göre Ortadoğu'ya yapılan ihracat, Türkiye'de yapılan toplam ihracatın \%22,5'ini, Ortadoğu'ya y apılan ithalat ise toplam ithalatın \%8,5' ini oluşturmaktadır. Ayrıca Türkiye'nin Ortadoğu ülkelerinden neredeyse tamamının üye olduğu İslam İş birliği Teşkilatına üye olması da dış ticaretin artmasını pozitif açıdan etkilemektedir (Engin Öztürk, 2018). Bu önermeyi 3,94 ortalama ile Lojistik köy sayesinde dış ticaret yapmak kolaylaşacaktır" önermesi takip etmektedir. Globalleşen dünyada uluslararası ticaretin artan önemine istinaden bu önermenin ortalamasının yüksek olması da beklenen bir bulgu olarak karşımıza çıkmaktadır. Yine 3,94 ortalaması ile "Lojistik köyü, Kahramanmaraş ilinin dış çevreye doğru bir biçimde tanıtımını sağlayacaktır", 3,91 ile "Lojistik köyü ile Kahramanmaraş'ın sınır komşuları arasında etkileşim daha fazla artacaktır" ve 3,90 ile "Lojistik köyler, ilimizdeki sanayi dışındaki diğer sektörlerin de gelişimine sinerji oluşturacaktır" önermeleri de yüksek ortalamaya sahiptirler. İlin dış çevre ile etkileşime girmesi, ticaret ve işbirliği yapması ve böylece doğru bir biçimde tanıtımının sağlanması bir ilin rekabetçiliğini etkileyen unsurlardan bir kaçıdır. Katılımcılar bu konuya yönelik de olumlu tutum sergilemişlerdir. Tüm bu değerler katılımcıların kararsız olmak ile katılmak arasında katılmaya daha yakın olduklarını ve pozitif bir bakış açısına sahip olduklarını ancak bu konuya dair yeterince bilgilerinin olmadığını göstermektedir.

“Lojistik köy nedeni ile nüfus artacağından ilimizde suç oranları artacaktır” önermesi 3,02 ile en düşük değere sahiptir. Bu önermeye verilen yanıtlara bakıldığında ise \%34,0'ü (52 kişi) kararsızken, \%31,4'ünün suç oranlarının artacağına inanmadıklarını; \%34,7' sinin ise suç oranlarının artacağını düşündüklerinin belirtmişlerdir. Bu önermeyi 3,11 ile "Lojistik köyler KOBi niteliğindeki işletmelere dezavantaj oluşturacaktır." önermesine izlemektedir. Katılımcıların \%44,4'ü (68 kişi) bu önerme ile ilgili kararsız olduklarını dile getirmişlerdir. "Lojistik köy nedeni ile nüfus artacağından ilimizde yol, su, elektrik gibi alt yapı hizmetlerinde ve sağık, eğitim gibi alanlarda hizmetler yetersiz kalacaktır” önermesi 
3,18 ortalama ile üçüncü düşük önermedir. Bu üç önerme de kararsıza yakın ortalamalara sahiptir. Daha çok karar veremeyenlerin olduğu görülmekle beraber konuya olumlu ya da olumsuz yaklaşanların da oranı birbirine oldukça yakındır. Aslında katılımcıların lojistik köyün avantaj sağlarken yanı sıra dezavantaj da yaratıp yaratmayacağına dair tereddütlerinin olması da şaşırtıcı değildir. Çünkü her yenilik ve değişim belirsizlik içermektedir.

Uygulanan ANOVA testi sonucunda katılımcıların lojistik kümelenme algılarına ilişkin önermelere verdiği cevaplarda çalışma süreleri ve lojistik kümelenme kavramını bilme düzeyleri arasında $(p=0,000 ; p \leq 0,05)$ anlamlı bir farklılık olduğu, cinsiyet, yaş, eğitim durumları açısından ise anlamlı bir farklııı olmadığı görülmektedir. Bu sonuçlar uyarınca H4: "Katılımcıların çalıştıkları yıla göre lojistik köy algısı arasında anlamlı bir farklılık vardır" ve H5: "Katılımcıların bilgi düzeyine göre lojistik köy algısı arasında anlamlı bir farklılık vardır" hipotezleri kabul edilmiş, H1, H2, H3 hipotezler ise reddedilmiştir.

Bu nedenle başta işletme çalışanları olmak üzere yöre halkının lojistik faaliyetlerin önemi ve lojistik kümelenmelerin faydaları ile ilgili ivedilikle bilgilendirilmeleri gerekmektedir. Bu noktada ilgili kamu kuruluşlarının, üniversitenin ve sanayinin iş birliğinin arttırılma sı, tüm paydaşların sürece dâhil edilmesi, lojistik merkezin tanıtımının yapıldığı kongre, sempozyum ve fuarların düzenlenmesi gerekmektedir. Kahramanmaraş Türkoğlu lojistik kümelenmesinin aktif hale gelmesi ile ilin ve ilçenin büyük kazanımlar edineceği beklenmektedir. Bu nedenle aktif olma sürecinin hızlanması ve yöre halkının bu sürece olabildiğince çabuk adapte olmalarının sağlanması gerekmektedir.

\section{KAYNAKÇA}

Akandere, G. 2013. "Lojistik Köylerin Etkin Yönetimi: Konya İline Yönelik Bir Model Önerisi”. Selçuk Üniversitesi, Yüksek Lisans Tezi, Konya.

Akçetin, E. 2010. “Avrupa Birliğine Üyelik Sürecinde Küresel Lojistik Üs Olma Yolunda Türkiye”. Adıyaman Üniversitesi, Sosyal Bilimler Enstitüsü Dergisi, 3(5).

Aydemir, B., Soydaş, M. E. 2014. “Denizli İli Turizm Kümelenme Potansiyeli”. Pamukkale Journal Of Eurasian Socioeconomic Studies, 1(2): 1326.

Bay, M., Erol, F., 2016. "Lojistik Köylerin Önemi ve İntermodal Taşımacılık Faaliyetleriyle Desteklenmesi”: Karaman İlinde Bir Uygulama. KMÜ Sosyal ve Ekonomik Araştırmalar Dergisi 18 (30): 124- 134, 2016 ISSN: 2147- 7833

Dursun, T., Gürsev, S., 2019. “Pazarlamada Dağıtım Kanalları Yönetimi ve Lojistik Merkezlerin Gelişiminde Kümeleme Yaklaşımı”. Marmara Üniversitesi Öneri Dergisi, 12(45). Doi:10.14783/Od. V12i45.1000020026

Engin Öztürk, B. 2018. "Türkiye-Ortadoğu Ülkeleri Arasındaki Dış Ticaret ve Sermaye Hareketleri”. Journal Of International Social Research, 11(60).

Eraslan, I. H., Dönmez, C. Ç., 2017. “Endüstriyel Kümelenme Uygulamalarının Türkiye Genelinde İncelenmesi: Sanayi, Tarım ve Hizmet Sektörleri Açısından Bir Değerlendirme”. Elektronik Sosyal Bilimler Dergisi, 16(61), 325-368.

Europlatforms. 2015. Corporate Presentation European Association Of Transport \& Logistics Centres. www.europlatforms.eu/

Gedik, H., Turğut, M., 2017. "Uluslararası Ticarette Lojistik Köylerin İhracat Sürecine Etkileri: Konya İli Örneği”. The Jour nal Of International Scientific Researches, 2, 129-147.

Gökdeniz, A. 2015. “Turizmde Kümelenme ve Bölgesel Kalkınma Üzerindeki Etkileri (Ayvalık'ta Kümelenme Potansiyeli ve AYTUGEB Örneği)”. International Journal Of Social And Economic Sciences (IJSES) E-ISSN: 2667-4904, 5(1): 37-48.

Günaydın, D. 2017. “Bölgesel Kalkınma Sürecinde Kümelenmeler: TR31 İzmir Bölgesi Örneği”. International Anatolia Academic Online Journal/Social Science Journal, 1(2): 11-47.

Gürbüz, A., Ayaz, N., Kebeci, S., 2016. “Üretim İşletmeleri Yöneticilerinin Lojistik Köy Algıları: Karabük ili Örneği”. Karabük Üniversitesi Sosyal Bilimler Enstitüsü Dergisi, Özel Sayı: 1-19.

Michael, E. J. 2003. “Tourism Micro-Clusters". Tourism Economics Journal, 9(2): 133-145.

TCDD., 2017. "2017 FaaliyetRaporu”. (Ed.): T.C. Devlet Demiryollarıİşletmesi Genel Müdürlüğü, Strateji Geliştirme Dairesi Başkanlığı, Stratejik Planlama Şubesi Müdürlüğü, www.tcdd.gov.tr/

Terzi, N., Bolukbas, O. 2016. "Türkiye' de Lojistik Sektörü ve Lojistik Köyler". Pressacademia Procedia, 2(1): $206-228$.

Yıldırım, K., Demet, E. 2016. Rekabet ve Değer Zinciri Çerçevesinde Lojistik Kümelenme Örnekleri Olarak Singapur Lojistik Kümelenmesi ve Ankara Lojistik Üssü. Trakya Üniversitesi Sosyal Bilimler Dergisi, 18(2): 395-420.

Zaralı, F., Yazgan, H. R., Delice, Y. 2019. AHP ve VIKOR Bütünleşik Yaklaşımıyla Lojistik Merkez Yer Seçimi: Kayseri İli Örneği. Erciyes Üniversitesi Fen Bilimleri Enstitüsü, Fen Bilimleri Dergisi, 34(3): 1-9.

http://www.sogaris.fr. Erişim tarihi 10.05.2019 